Materiales de Construcción

Vol. 68, Issue 329, January-March 2018, e146

ISSN-L: 0465-2746

https://doi.org/10.3989/mc.2018.10216

\title{
Static and cyclic performance of cementitious composites reinforced with glass-fibres
}

\author{
N. Arabi凶 \\ Materials Geomaterials and Environment Laboratory, Badji Mokhtar-Annaba University, (Annaba, Algeria) \\ $\bowtie$ nourredine.arabi@univ-annaba.dz; nourredine_arabi@yahoo.fr
}

Received 5 September 2016 Accepted 12 May 2017 Available on line 6 March 2018

\begin{abstract}
This paper concerns an experimental study of the influence of short glass-fibres randomly oriented of a reinforced cement-based composite on the mechanical behaviour. The matrix material parameters used are: cement/sand ratio and water/cement ratio fixed at 0.5 ; the glass-fibre content $(0 \%, 0.5 \%, 1.0 \%, 1.5 \%, 2 \%$ and $2.5 \%)$ and fibre lengths $(3,6$ and $12 \mathrm{~mm})$. Composites mechanical characterisation under static behaviour at flexural and compression tests, shows that the reinforcement effect is beneficial only in flexural case. A synergy (matrix-reinforcement) was observed when fibre length of $12 \mathrm{~mm}$ is used with application rate of $2 \%$ in flexural. The fatigue behaviour determined by Wöhler plots (stress-number of cycles to rupture), derived from experimental results; showed a large results dispersion which is attributed to many causes initiating this damage. The cyclic tests illustrate brittle character of these materials; even with low-amplitude cycles of loading no adaptation of these materials can be reported.
\end{abstract}

KEYWORDS: Alkali; Glass; Fibre reinforcement; Flexural strength; Fatigue

Citation/Citar como: Arabi, N. (2018) Static and cyclic performance of cementitious composites reinforced with glassfibres. Mater. Construcc. 68 [329], e146. https://doi.org/10.3989/mc.2018.10216

RESUMEN: Rendimiento estático y cíclico de compuestos cementantes reforzados con fibras de vidrio. Este trabajo aborda el estudio experimental de la influencia de fibras de vidrio cortas orientadas al azar sobre el comportamiento mecánico de un composite reforzado de base cemento. Los parámetros de la matriz utilizados son: relación cemento/arena y relación agua/cemento fijada en 0,5 ; el contenido de fibra de vidrio $(0 \%, 0,5 \%, 1,0 \%$, $1,5 \%, 2 \%$ y $2,5 \%$ ) y longitudes de fibra $(3,6$ y $12 \mathrm{~mm})$. Los resultados mecánicos de estos compuestos bajo comportamiento estático (flexión y compresión), muestran que el efecto de refuerzo es beneficioso unicamente a flexión. Se observó una sinergia (refuerzo de la matriz) cuando se usó la fibra de $12 \mathrm{~mm}$ con una tasa de aplicación del $2 \%$ en flexión. El comportamiento a fatiga determinado por las curvas de Wöhler (número de ciclos hasta la rotura), derivado de los resultados experimentales; mostró una gran dispersión de resultados que se atribuye a las muchas causas que pueden iniciar este daño. Las pruebas cíclicas ilustran el carácter quebradizo de estos materiales; y no se pude indicar que exista adaptación de estos materiales, incluso con ciclos de carga de baja amplitud.

PALABRAS CLAVE: Álcalis; Vidrio; Refuerzo de fibras; Resistencia a la flexion; Fatiga

ORCID ID: N. Arabi (https://orcid.org/0000-0001-5381-2422)

Copyright: (C) 2018 CSIC. This is an open-access article distributed under the terms of the Creative Commons Attribution 4.0 International (CC BY 4.0) License.

\section{INTRODUCTION}

The reinforcement in reinforced concrete improves the tensile strength, but has no effect on microcracking. To reduce this, the use of fibre is highly recommended (1). In addition, fibre-reinforced concrete is frequently used as a repair material $(2,3)$. The cementitious matrix strengthening with fibres, relatively short and evenly distributed in volume, prevents the growth of micro-cracks by forming 
a bridge between the crack lips, if it happens to expand (4). The fibres serve to inhibit unstable crack propagation.

Products like fibre-cement in the past, asbestosbased are currently prohibited for health reasons: so it is recommended to replace this asbestos by fibres of different type to keep mechanical qualities. The asbestos fibres reinforced cement usually maintain their high flexural strength over time (5). The glassfibre is perhaps the substitute material the most common and widely recognised form of fibre reinforcement. The composite is commonly so-called "glass-fibre reinforced cement (GFRC)". The presence of a minimum volume content of short fibres is then necessary, so as to optimise the benefits of the incorporation of these. The influence of fibre nature is presented in the report prepared by Rilem Technical Committee (6). An excess of fibres affects the workability of fresh mix. If the metallic fibres are easily dispersed at contact with water of fresh mortar $(7,8)$, the same is not true for the glass-fibres which remain in multifilament yarn (in the form of bundles). The glass-fibres are generally characterised by their length and not by their slenderness ratio $(9,10)$. This ratio is defined as the fibre length/ diameter ratio $\left(l_{f} / d\right)$. Length, typical and content of fibres lead to the increase in strength, cracking resistance and toughness $(11,12)$.

This study is based on mechanical follow-up the damage up to rupture under static loading where the effect of the addition of glass-fibres on mechanical behaviour was analyzed. In addition, an investigation was also conducted on behaviour under cyclic load on the GFRC samples. In this context, the cement matrix composites were the subject of many experimental works on fatigue studies for decades, which relate much more on concrete reinforced with metallic fibres. However, few studies were conducted on glass-fibres under cyclic loading and those that were carried out concern the matrix other than cement (14).

Fatigue studies are usually restricted at plotting $S-N$ diagrams (stress-number of cycles) and the determination of a probable endurance limit for specific test conditions $(15,16)$. Endurance limit requires a large number of tests to determine the fatigue limit below which the material is not sensitive to fatigue phenomenon. In practice, the determination of the endurance limit for cementitious materials is difficult to achieve due to the random nature of the fatigue rupture in areas with limited endurance (17). The only reliable methods for assessing the endurance limit rely on statistical methods (18). According to a synthesis of Lee and Barr (19), presenting a general review of the results of fatigue performance of plain concrete and fibre reinforced concrete, in order to obtain a limit of endurance more than 1 million cycles are required which is also reported by Naaman and Hammoud (15). In this synthesis, the authors concluded that the fibre volume content appears to be the main factor in fatigue. However, the same authors consider the $l_{f} / d$ ratio is a secondary parameter in the fatigue life; while it is considered as the main parameter increasing cracking resistance and toughness in the static load situation.

The present study aims to investigate the influence of fibre length and content on the physical and mechanical properties of the cement matrix composites under static and cyclic loads.

\section{MATERIALS AND METHODS}

\subsection{Materials}

The CEM II/B 32.5R is the type of cement used in this study and is manufactured by Cement Lafarge Ltd (France), conform to EN 197-1 (the European standard) (20). Its chemical composition is given by the manufacturer and presented in Table 1. In addition, the sand used is a siliceous fraction that does not exceed $500 \mu \mathrm{m}$ in size (see Figure 1). To improve the fresh mixture workability, the superplasticiser Sikament FF86 (High Range Water Reducing Admixture), conform to ASTM C494-86 (ASTM standard) (21) is added to the mix. Its physical and chemical characteristics are given in Table 2.

The studied fibres are alkali resistant glass-fibres (A-R glass-fibres), from Saint Gobain Vetrotex manufacturer. Each yarn is composed of 204 filaments each having a diameter of about 10 microns (Figure 2). The fibres are $\mathrm{ZrO}_{2}$-rich (16.6 weight \%) and this will protect the fibres from the alkaline attacks of the cement matrix (22). The major physical and mechanical properties, given by the manufacturer, are displayed in Table 3.

\subsection{Methods}

Two series of prismatic specimens of $40 \times 40 \times$ $160 \mathrm{~mm}^{3}$ were prepared: for control samples and GFRC samples with glass-fibres content at (vol. fractions: $0.5,1,1.5,2$ and $2.5 \%$ ), the fibre volume fraction replaces an equivalent volume of sand. Three fibre lengths 3, 6 and $12 \mathrm{~mm}$ were used.

TABLE 1. Chemical composition of cement (\% wt.)

\begin{tabular}{cccccccccccc}
\hline Elements & $\mathbf{S i O}_{2}$ & $\mathbf{A l}_{2} \mathbf{O}_{3}$ & $\mathbf{F e}_{2} \mathbf{O}_{3}$ & $\mathbf{C a O}$ & $\mathbf{M g O}$ & $\mathbf{K}_{2} \mathbf{O}$ & $\mathbf{N a}_{2} \mathbf{O}$ & $\mathbf{S O}_{3}$ & $\mathbf{C l}^{-}$ & Insolubles & Loss on ignition \\
\hline & 25.05 & 8.6 & 3.5 & 55.4 & 0.9 & 1 & 0.15 & 2.7 & 0.022 & 11.8 & 2.2 \\
\hline
\end{tabular}




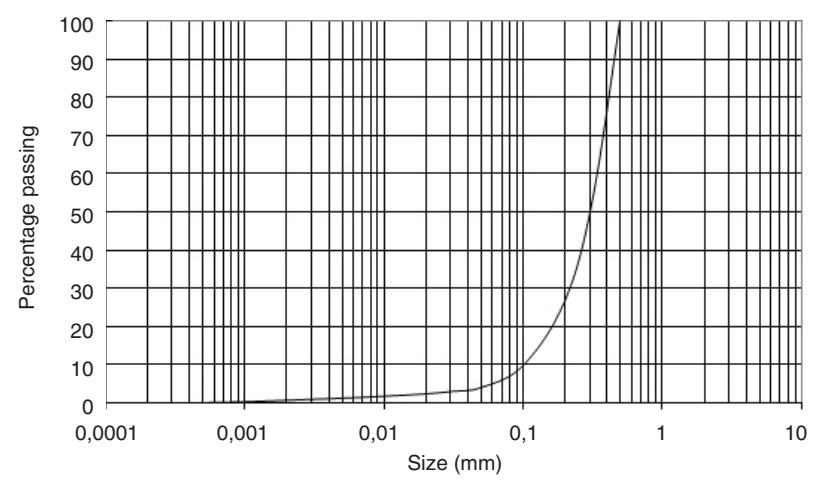

FIGURE 1. Particle size distribution of sand.

TABLE 2. Physical and chemical characteristics of the superplasticiser Sikament FF86

\begin{tabular}{lc}
\hline & Aqueous solution \\
\hline Density & 1.23 \\
$\mathrm{pH}$ & $7-11$ \\
$\mathrm{Cl}^{-}($weight $\%)$ & $<0.1$ \\
$\mathrm{Na}_{2} \mathrm{O}$ equivalent (weight $\left.\%\right)$ & $<6.0$ \\
\hline
\end{tabular}

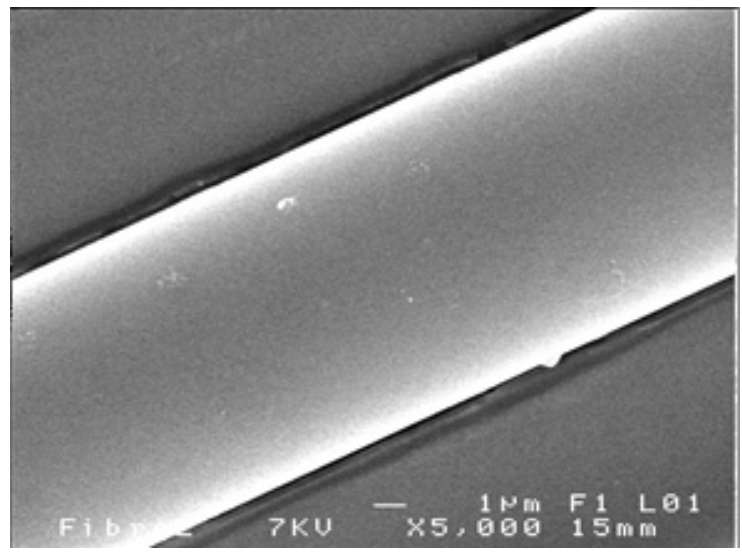

FIGURE 2. A-R glass-fibre (alkali resistant glass-fibre).

TABLE 3. Physical and mechanical properties of A-R glass-fiber

\begin{tabular}{lc}
\hline Density & $2.68 \mathrm{~g} / \mathrm{cm}^{3}$ \\
Tensile strength : virgin filament & $3000 \mathrm{MPa}$ \\
Tensile modulus & $73000 \mathrm{MPa}$ \\
Elongation at break & $4.30 \%$ \\
Coefficient of linear thermal & $5.10^{-6} \mathrm{~m} / \mathrm{m} / \mathrm{K}$ \\
expansion (between 20 and $100^{\circ} \mathrm{C}$ ) & $773^{\circ} \mathrm{C}$ \\
\hline Flammability & \\
\hline
\end{tabular}

To resolve the workability problem of composites associated with effectiveness a maximal addition of fibres, a superplasticiser up to $1 \%$ of cement weight was used. For all mix designs studied, the water/cement ratio and cement/sand ratio were maintained constant at 0.5 . After demoulding, all the specimens were cured in a moist room (temperature of $20^{\circ} \mathrm{C}$ and humidity of $95 \%$ ) and tested at the ages of 7, 14 and 28 days.

The static tests were conducted for the flexural tensile strength to the three point loading flexural on prismatic specimens of $40 \times 40 \times 160$ $\mathrm{mm}^{3}$ using a hydraulic press and the measuring of vertical deformation is recorded by a LVDT (Figure 3). Compressive strength test was performed on half of the sample with a bearing surface of $40 \times 40 \mathrm{~mm}^{2}$.

To determine the elasticity modulus and Poisson's ratio, axial compression tests were performed on the cylinder specimens of $\varnothing 50 \times 100 \mathrm{~mm}$ using a hydraulic press. In addition, two strain gauges bonded at the cylinder's mid-height were used to measure specimens axial and hoop strains, as shown in Figure 4. A strain acquisition system (VISHAY type data

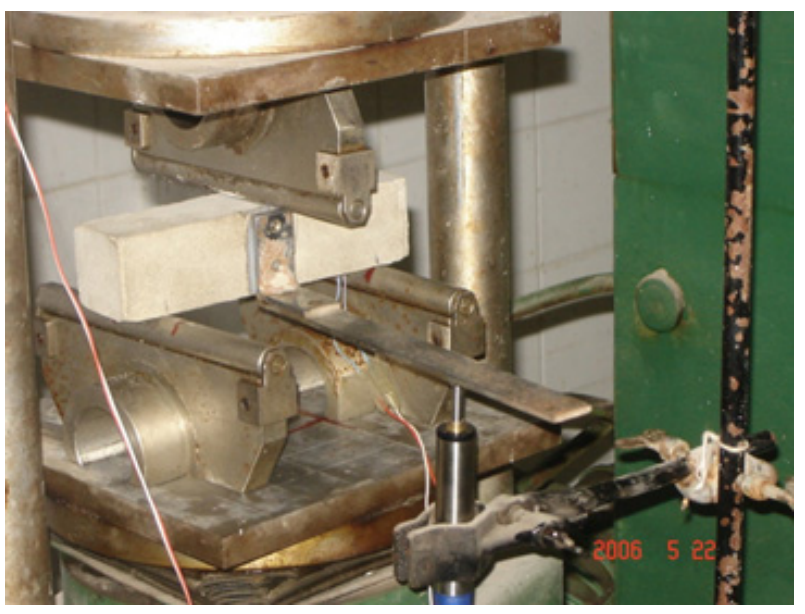

FIGURE 3. Three point bending test setup.

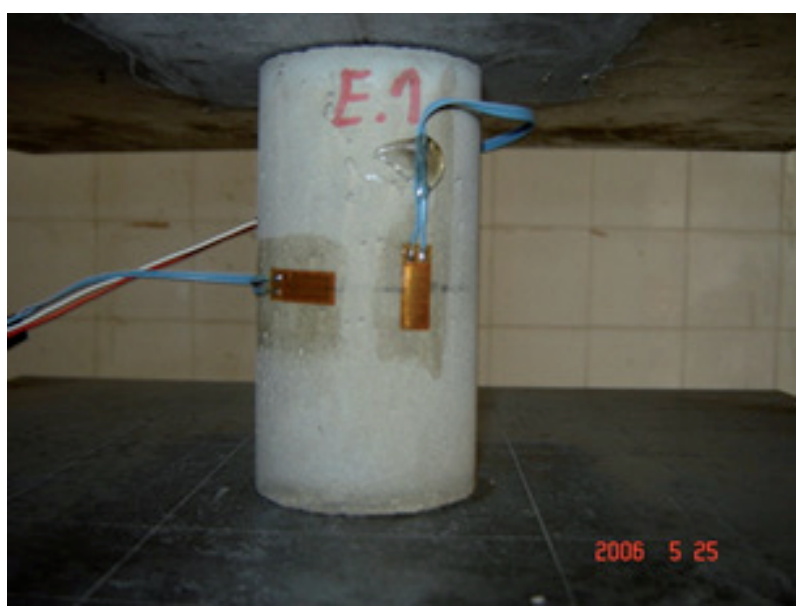

FIGURE 4. Test setup of the cylinder GFRC. 
acquisition, model 5100B Scanner) was used to record the displacement and strain data. This system enables to take up to 10 points per second. Before testing, the upper and lower surfaces of each cylinder specimen were adjusted with a grinding machine, to eliminate loading eccentricity.

Cyclic fatigue tests were performed with a servo-hydraulic testing machine equipped with a force sensor of $5 \mathrm{kN}$ and connected to a data acquisition system. The cyclic load applied was corrugated, in this situation the fatigue stress ratio was $R=o_{\min }^{\prime} / o_{\max }=0.16$ using an imposed load with three-point bending test and the test frequency is $1 \mathrm{~Hz}$, which is constant for all load levels. The values of $\sigma_{\min }$ (minimum stress) and $\sigma_{\max }$ (maximum stress) correspond to $10 \%$ and $70 \%$ of ultimate stress of static loading, respectively. The prismatic specimens of $40 \times 40 \times 160 \mathrm{~mm}^{3}$ are used and the fatigue tests were carried out after 28 days of curing under room temperature conditions.

To conduct cyclic tests, the loading process was conducted as follows: to proceed a first static loading up to impose a tensile stress by bending corresponding to $\sigma_{\max }$. Then, the unloading is conducted in order to reach $\sigma_{\min }$. Thereafter begins the cycling between $\sigma_{\min }$ and $\sigma_{\max }$ as stress range until to rupture. Figure 5 shows an example of cycling between $\sigma_{\min }$ and $\sigma_{\max }$ as hysteresis curve according to displacement of the crosshead of fatigue testing machine. For each load level change was performed a loading speed change (crosshead speed) to maintain a constant frequency of $1 \mathrm{~Hz}$. Cyclic tests were carried out on three types of samples reinforced with $0,0.5$ and $1.5 \%$ fibres. For each mix, five different target load ranges were applied: $10-30 \%, 10-40 \%, 10-50 \%, 10-60 \%$ and $10-70 \%$ of the ultimate flexural capacity, as obtained from the corresponding to static loading. The loading cycles are repeated many times until rupture takes place and the test is repeated 3 times for each load range. For the purpose of $S-N$ diagrams plotting, the number of cycles to rupture was noted.

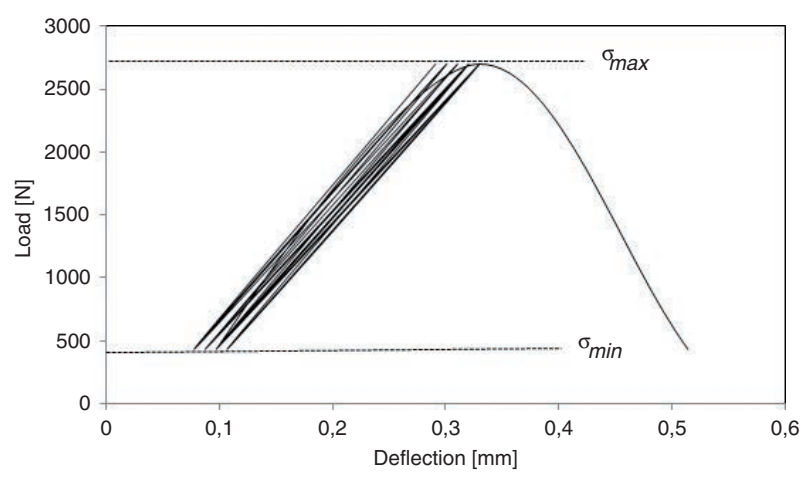

Figure 5. Example of hysteresis load to cycling between $\sigma_{\min }$ and $\sigma_{\max }$.

\section{RESULTS AND DISCUSSION}

\subsection{Static results}

\subsubsection{Flexural behaviour}

Figure 6 illustrates an example of load/deflection curves obtained from the reference sample (without fibres) and the samples reinforced with glass-fibre content by $2 \%$ having fibre lengths of 3,6 and $12 \mathrm{~mm}$. With short fibres $(3$ or $6 \mathrm{~mm}$ ), the behaviour was similar to that of the reference sample. The curves are almost linear up to rupture; they show brittle fracture behaviour. Whereas, the sample reinforced with fibre length of $12 \mathrm{~mm}$, the curve shows three phases: one elastic linear phase, followed by another no-linear phase showing an evolution of damage due to a development of micro-cracks in the material. In this state, more and more relatively fine cracks are formed gradually due to the increase in the stress. The length and smoothness of this portion of the curve depend on the quality of the bond between fibre and matrix, which is activated for load transfer. As shown in Figure 6, the effectiveness of the fibre length of $12 \mathrm{~mm}$ is quite obvious. Indeed the appearance of this part of the stress-strain relation can be related to the number and widths of cracks (10). The final state corresponds to phase "post-peak behaviour after the maximum load", or the existing cracks become wider until the tensile strength of the fibre is reached and the composite fails. It is, though, precisely at this post-cracking stage, that fibres become more efficient and show their true effectiveness. However, no significant ductility was perceptible as that obtained in similar cases using metallic fibres $(4,7)$, but what seems to appear is a pseudo-ductility. This phase can also be called residual phase, due precisely to fibre total debonding and fibre-matrix friction. The fibres used in this study have a critical fibre length (loadtransfer length) below the real length of the fibres.

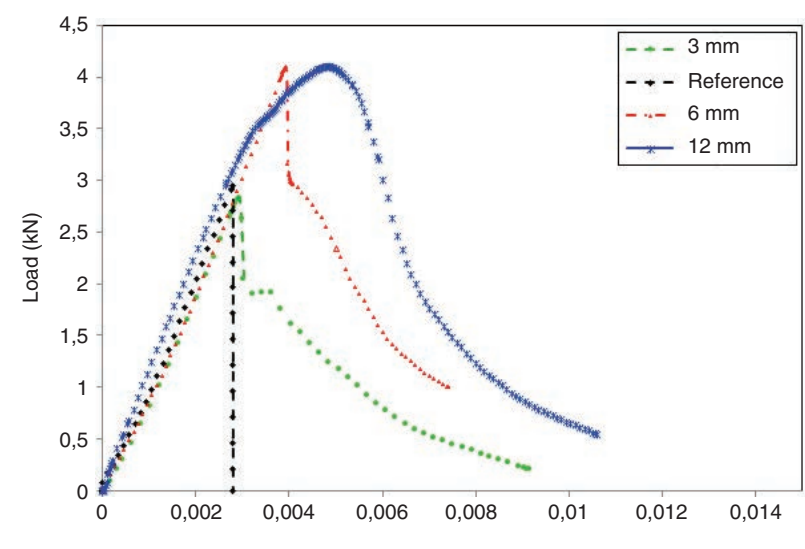

Figure 6. Load-deflection curves of reference sample and samples reinforced with $2 \%$ glass-fibres. 
(a)

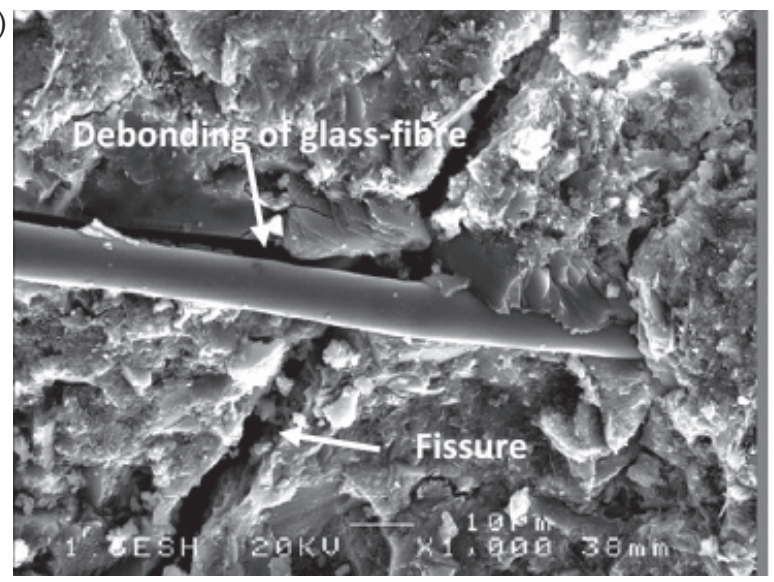

Fissure from either side the fibre without breaking it

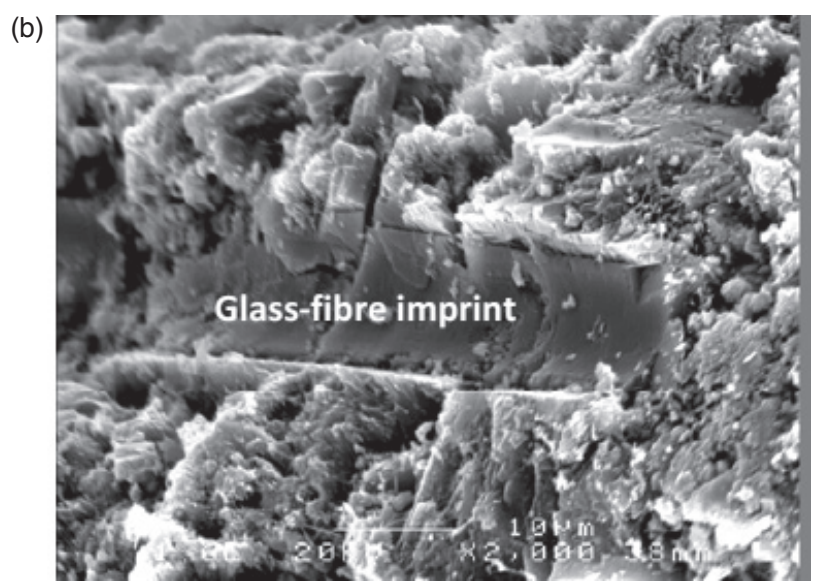

Débonding of fibre leaving an imprint

FIGURE 7. SEM image showing an interfacial debonding of glass-fibre.

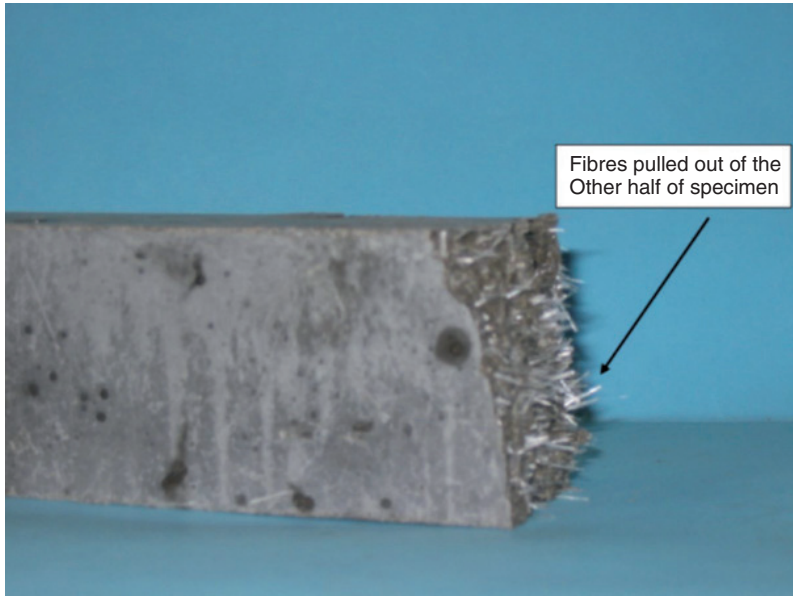

Figure 8. Glass-fibre unstuck of matrix following a bending test.

In this case, the fibre rupture has not occurred, but the debonding of glass-fibre was observed as illustrated in Figures 7 and 8.

Figures 9 and 10 show the results of flexural strength at 7 and 28 days of curing for the three fibre lengths used depending on the glass-fibre content. Results dispersion appears which is related to the heterogeneity of granular materials and largely at the random distribution and variable (length and content) of the fibres.

The presence of fibre length of $3 \mathrm{~mm}$ in a cementitious matrix has virtually no influence on the flexural tensile strength, even when the fibre volume fraction varies. The improvement is noticed with increasing fibre length and when the content is also increased, in the case of glass-fibre lengths of 6 and $12 \mathrm{~mm}$. It should be noted that for reinforced samples at rates less than $2 \%$ of fibres present results with more or less significant variances

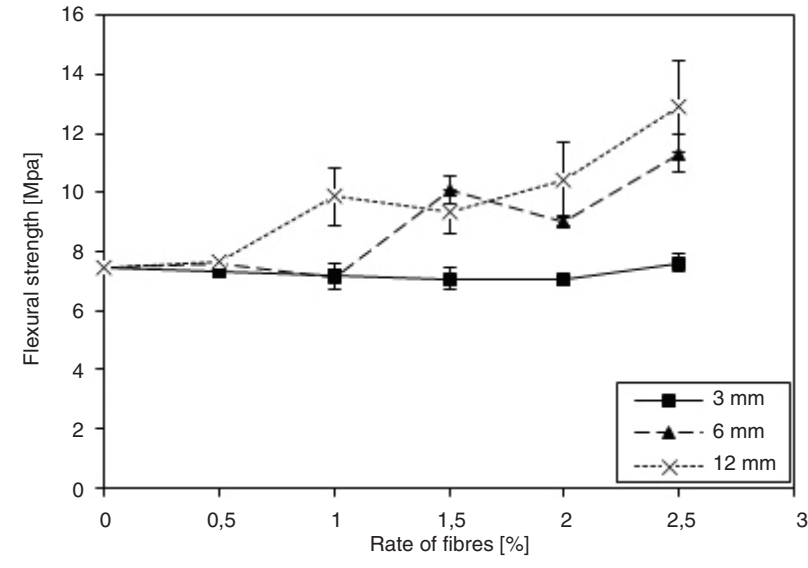

FIGURE 9. Flexural strength at 7 days of curing.

(resistances obtained at 7 days of curing). However, these variances of results become less significant at 28 days of curing. This is probably due to the matrix maturity on the mechanical performance as reported by Rossi (8). The fibre-matrix bond (or interfacial bond), and thereby the load transfer through the fibre on either side of the micro-crack, improves with the curing time. At 28 days of curing, the matrix develops a sufficient maturity to withstand the loads and the fibres appear to have little influence due of their degradation in an alkaline environment of cement paste as reported in a previous paper (26). The benefits of the fibres were more distinguished with the length of $12 \mathrm{~mm}$ and a glass-fibre content of $2 \%$. Nevertheless, a significant effect affects the stress transfer that is the fibrematrix bond. As reported by Bentur and Mindess (1), the reinforcing bundle remains as a flexible unit even after 28 days of curing, with each filament having a considerable freedom of movement compared to the others. Some stress transfer into the inner 
filaments may occur through frictional effects, aided by the point contacts formed by the hydration products and the sizing applied during the production of the glass-fibre strands. In such a bundle, the bonding is not uniform, only the external filaments are more tightly bonded to the matrix. However, among these hydration products, there's the formation of the portlandite or the calcium hydroxide $\left(\mathrm{Ca}(\mathrm{OH})_{2}\right)$, having a very fine particle size $(<1 \mu \mathrm{m})$, that fills spaces between and around the glass fibre filaments, thus, cementing them together and reducing their flexibility. This causes excessive bonding and local concentration of stresses under load at the surface of fibres, resulting in embrittlement of GFRC. An example is illustrated on Figure 11 showing the deposition of portlandite into the spaces between fibres (26).

In addition, the glass-fibres are randomly distributed in the matrix and taking directions in threedimensional(3D) reinforcing. This occurs when fibres

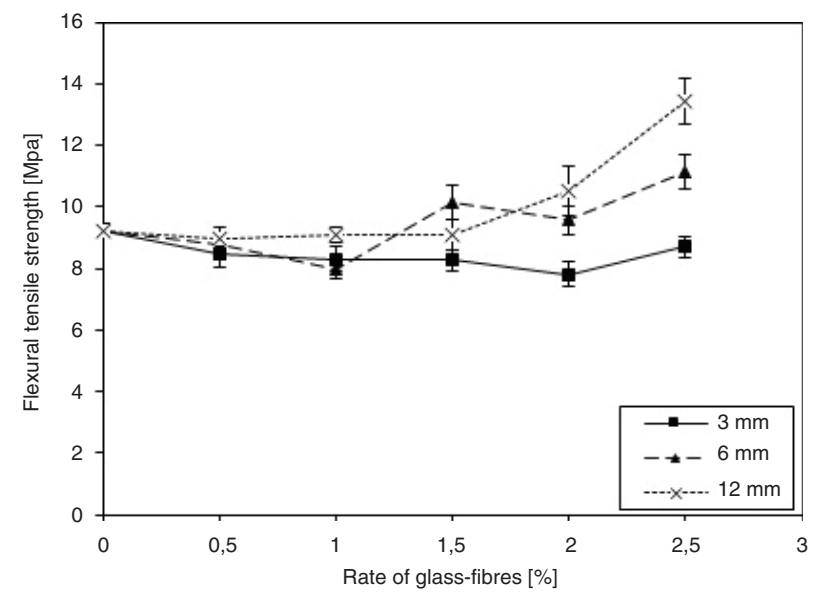

FIgURE 10. Flexural strength at 28 days of curing.

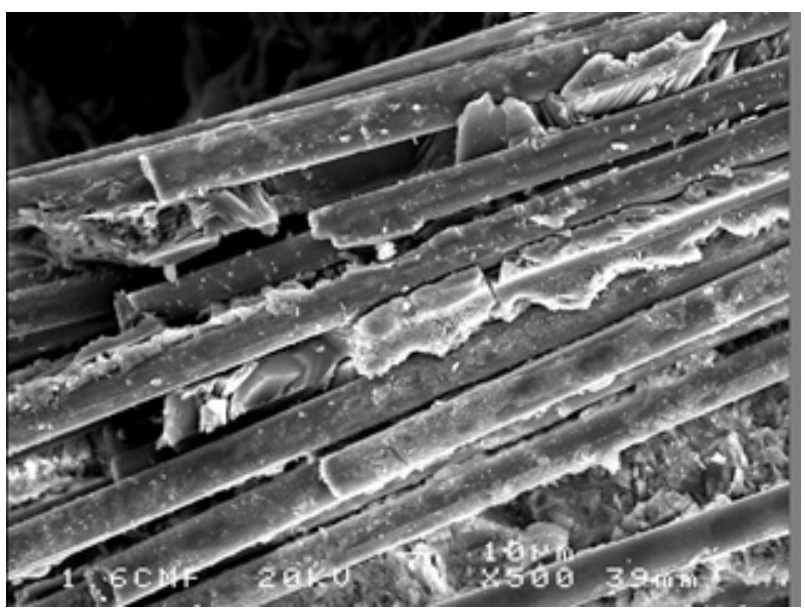

FIGURE 11. Filling of the spaces between the glass-fibre filaments by calcium hydroxide. are mixed into the concrete and poured into forms, as this studied case or the mix is poured into moulds. In this way, the fibres are evenly distributed in all concrete mixture and point in every direction. The orientation of the fibres in the mix is also important; it is required to have more fibres to resist the loading. That's because on average, only a small fraction of randomly oriented fibres is oriented in the right direction. Due to the random and 3D orientation, very few fibres are able to resist tensile loads that develop in a specific direction. This configuration of fibre reinforcement is inefficient, requiring very high volume content of fibres. Typically, only about $15 \%$ of fibres are oriented correctly as reported by Jeff Girard (27). The SEM image (Figure 12) shows a similar case as the one described by this author, where the glass-fibres pointing in all different directions is observed.

To obtain information on the ductility of the material and the fibres contribution in energy terms dissipated; the Figure 13 shows the calculation of the strain energy, which corresponds to the area under the load/deflection curve defined by the points $\mathrm{O}, \mathrm{A}$, $\mathrm{B}$ and $\mathrm{C}$. These points are defined as follows:

- O: represents the curve origin,

- A: corresponds to the opening of the first crack (limit of phase linear),

- B: shows the maximum post-cracking,

- C: characteristic estimation of the test end.

The material is considered in a state of ruin when the measured load is equal to one-third of the load at the maximum post-cracking (23) and in Figure 13 the point $\mathrm{C}$ illustrates this case. Hence, this approach is similar to those used by the ASTM C 1018 (14) and JCI-SF 4 standard (25) and which allows the calculation of dissipated fracture energy for the range between 0 and $1 / 3$ of the load at the maximum

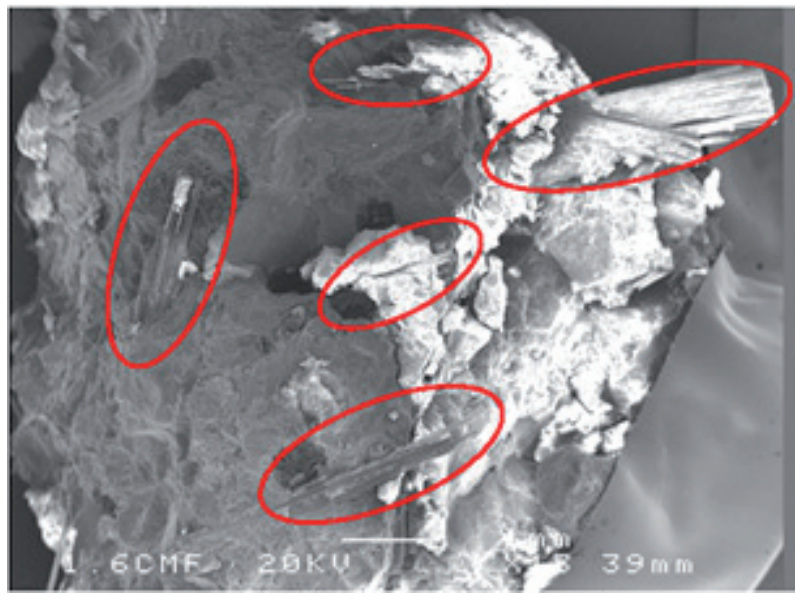

FIGURE 12. SEM image showing of glass-fibres point in all different directions in cement matrix. 
post-cracking; i.e., between two points of the curve (between $\mathrm{O}$ and $\mathrm{C}$ ). The share of strain energy devoted to the opening of the first crack (point A) is

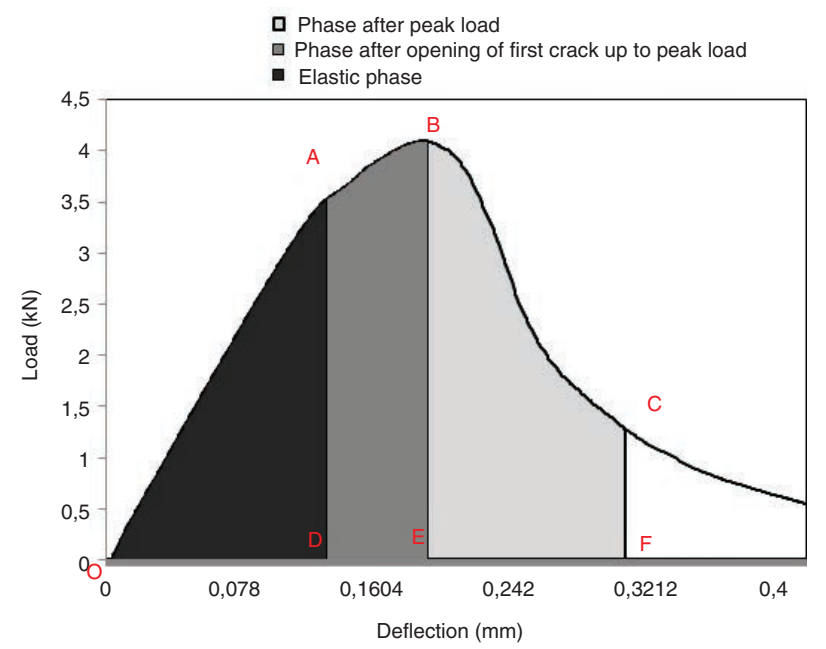

FIGURE 13. Distribution energy dissipated to break the specimen completely.

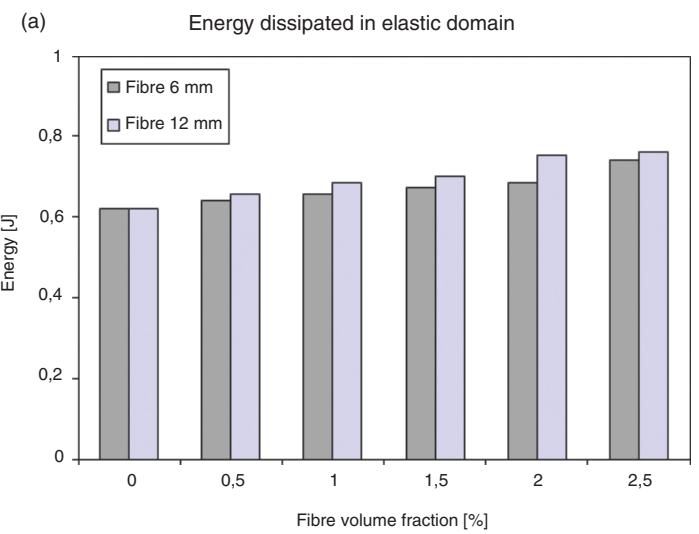

(c) Percentage distribution of energy dissipated for fibre length of $6 \mathrm{~mm}$

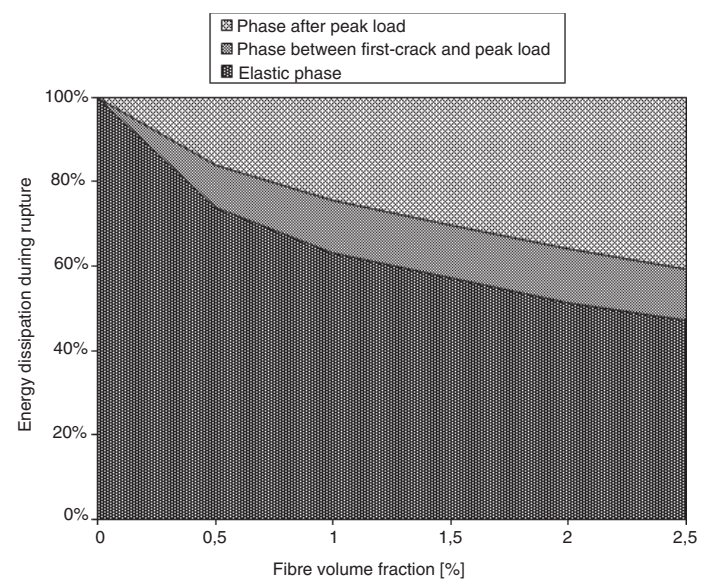

relatively low, and is about $30 \%$ of the total energy dissipated. This energy is required to achieve the maximum post-cracking (point B) represents only $45 \%$ of the total energy dissipated during the test. This result clearly demonstrates the contribution of fibres as residual strength, if this is considered to the post-peak strength.

To clarify the effect of fibre length and content of glass-fibre on the flexural toughness of GFRC, we present the Figure 14. The flexural toughness was evaluated by the calculation of the strain energy, which corresponds to the area under the load/deflection curve for three different phases, i.e., in elastic phase (area OAD), in phase after opening of firstcrack up to peak load (area ABED) and in phase after peak load (area BCFE), as shown in Figure 13. At first sight, the amount of energy dissipated increases, according to the increase of fibre length and content of glass-fibres (as in Figure 14). The energy dissipated in elastic domain for reinforced samples remains relatively the same, despite the change of fibre length and fibre volume fraction and does not present a substantial difference compared with energy dissipated during the rupture of reference sample (Figure 14a).
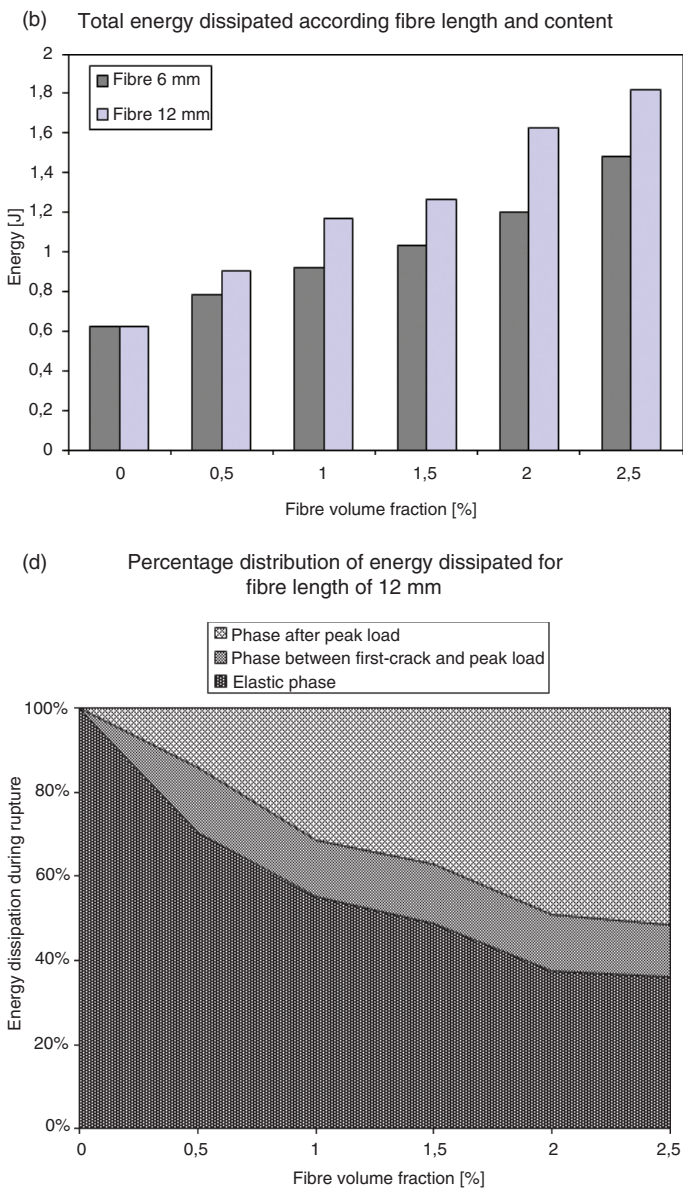

FIGURE 14. Effect of fibre length and content of glass-fibre on the flexural toughness of GFRC. 
This shows that the linear elastic domain is much more controlled by the matrix strength and the contribution of fibres is non-significant in this domain. The beneficial effects of fibres have become more tangible in post-linear elastic domain, i.e., after first cracking. They are all the more significant when fibre length and content increase, as shown in Figure 14b. This figure shows an increase of rupture energy about 3 times for the reinforced sample with fibre volume fraction equal to $2.5 \%$ and the fibre length of $12 \mathrm{~mm}$, in comparison to reference sample. This clearly indicated the benefits of fibres for the ductility of composite, while for the same configuration the value of ultimate bending strength has not increased as much. The increase of rupture energy is the direct result of an increase of the deformability of composite that of an increase in value of the ultimate rupture load. Figures 14c and 14d illustrate the percentage distribution of energy dissipated in areas OAD, ABED and BCFE. On these two figures is represented the energy dissipated during the test concerning each area, according to the fibre volume fraction used. It was noted a drop the share of energy dissipated in the elastic phase when the fibre volume fraction increases. However, the energy devoted at the post-cracking maximum phase shows an increase. We also observed than the energy dissipated during in no-linear phase, i.e., after the opening of first-crack up to peak load; remains relatively constant and does not change with the changes of fibre length and content. The phase after the appearance of first-crack is unstable and several phenomena combine both: early damage to the fibre-matrix interface, partial debonding of some fibres with always an increase in breaking stress but this all in a relatively short deformability area. This area does not appear to be a significant phase of the behaviour of GFRC. Increasing the fibre length is highlighted principally in the post-cracking maximum and particularly for the fibre length of 12 $\mathrm{mm}$. The fibre of $12 \mathrm{~mm}$ compared to that of $6 \mathrm{~mm}$ will require a significant load for its debonding from the matrix, it also develops of intense frictions with the matrix by multiplying the fracture surfaces. The fibre volume fractions are also highlighted especially for rates of 2 and $2.5 \%$, where the energy dissipated in the post-cracking maximum area represents half of the total energy and most notably with the fibre length of $12 \mathrm{~mm}$. By their numbers, the fibres act on the micro-cracks and the fibre length, more it is sufficiently long to ensure a good anchoring, acts on the macro-cracks.

To illustrate the influence of the fibre contribution on the flexural strength, a comparison is shown in Figure 15 between the experimental results and the derived results of the model of the law of mixtures. Swamy and Mangat (7) have presented a theory to predict the flexural tensile strength of concrete reinforced with short, discontinuous steel fibres randomly oriented and uniformly dispersed

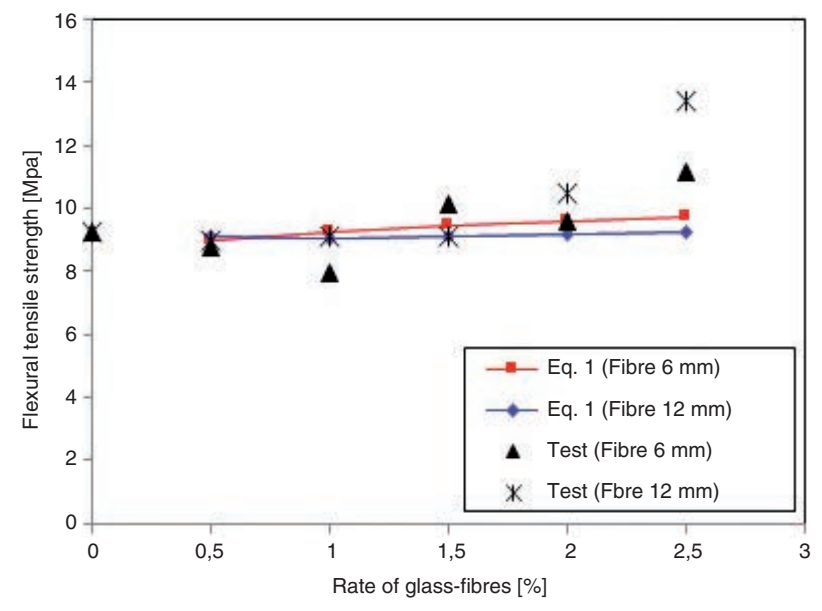

FIGURE 15. Effect of fibres on flexural strength.

in a cement-based matrix. The law states that the flexural tensile strength of concrete $\boldsymbol{\sigma}_{c u}$ should account for both the flexural strength of the plain matrix $\boldsymbol{\sigma}_{m}$ and a contribution from the fibres length $\boldsymbol{l}_{\boldsymbol{f}}$, diameter $\boldsymbol{d}$ and fibre volume fraction $\boldsymbol{V}_{\boldsymbol{f}}$, through the expression presented below:

$$
\sigma_{c u}=0.97 \sigma_{m}\left(1-V_{f}\right)+3.41 V_{f}\left(\frac{l_{f}}{d}\right)
$$

Only the experimental results of flexural strength at 28 days curing are taken into consideration to validate the model of the law of mixtures. Due to the specificity of glass-fibres which remain in the form of bundles, the parameter $\frac{l_{f}}{d}$ of the model was taken as being the fibre length. The evolution of flexural strength of the model increases in proportion to the increase of fibre content as shown in Figure 15. In contrast, we don't distinguish the contribution of fibre length, the two curves of the model of the fibre lengths 6 and $12 \mathrm{~mm}$, are almost superimposed. The theoretical curves are well situated within the range made by the experimental points. For the fibre volume fractions greater than $1.5 \%$; the equation [1] is not in good agreement with the flexural strength test data shown in Figure 15. This observation can be attributed to fibres effect and also to the dispersion of experimental results which are not considered by the model. This suggests that the model as formulated cannot be used as a tool to predict the flexural tensile strength of materials with large fibre volume fractions.

The application of the law model of mixtures shows that the glass-fibres do not have an obvious influence on the flexural strength and analysis of equation [1] illustrates this perfectly. The first term of the equation which accounts for the contribution of the plain matrix at the flexural strength forms the bulk of the composite strength. Whereas, the second 
term of the equation corresponds to a low contribution at the flexural strength. This demonstrates that the flexural tensile strength of GFRC is well governed by that of the matrix where the resistance to the occurrence of the first crack is the important part. The strength gain obtained in post-cracking is attributed to the contribution of the fibres remains very low, as shown in Figure 16. It should be noted that the applied model does not take into account the limits of material feasibility, i.e., the flexural strength evolves with increasing fibre content, while there is a fibre addition threshold beyond which the placing is impossible.

\subsubsection{Compressive behaviour}

Figure 17 shows an example of load/deflection curves obtained in compressive test for reference sample (without fibres) and the samples reinforced with glass-fibre content of $2 \%$ with fibre lengths of $(3,6$ and $12 \mathrm{~mm})$. These curves are typical granular materials subjected to a uniaxial compressive stress. The curves of the samples reinforced with

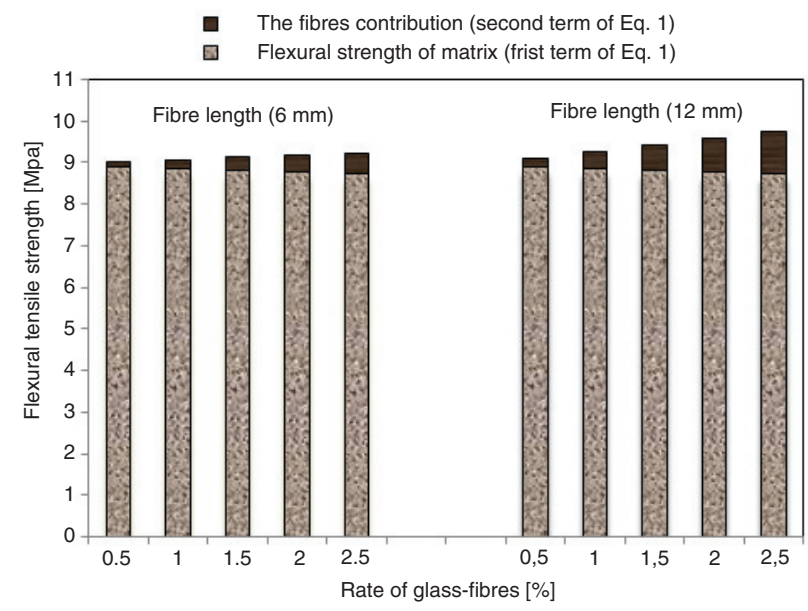

Figure 16. The fibres contribution to the flexural strength relative to the flexural strength of matrix according Eq.1.

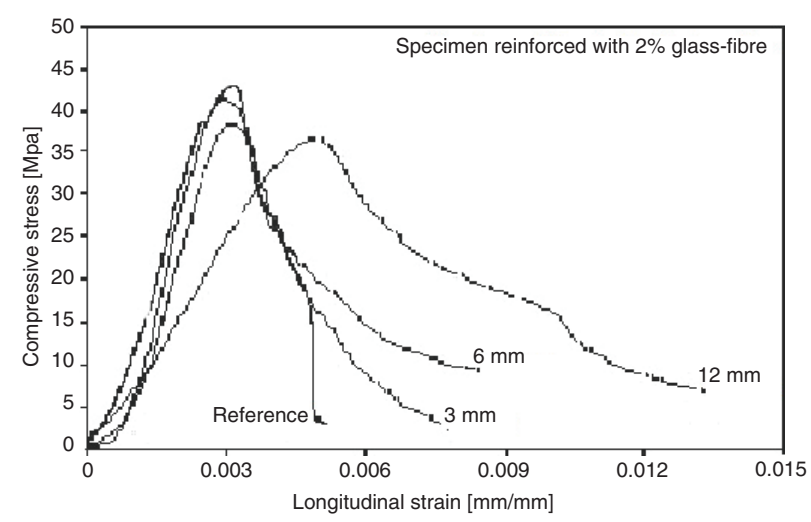

FIGURE 17. Stress-strain deformation in compression of GFRC. fibres are more stretched than the reference sample which results in a less steep incline thus giving to the reinforced materials a softening behaviour character. Fibre lengths are highlighted; shorter fibres are involved in a very small scale close to the order of the size of the used materials (sand). The short fibres delay the appearance of oblique cracks and consequently the compressive strength increases. On the other hand, the long fibres interpose at the level of oblique macro-cracks propagation (28).

The axial and hoop load-strain curves of the cylinders tested in this study are illustrated in Figure 18. Three specimens of GFRC experiments, reference sample (without fibres) and the samples reinforced with glass-fibre length of $12 \mathrm{~mm}$ at fibre volume fractions 1 and $2 \%$, were tested. A similarity appears on the two types of axial and hoop strains. The GFRC reinforced with fibres has a strain at fracture in compression significantly higher than that obtained for the reference sample and the situation is the same when the fibre content increases from 1 to $2 \%$. The curves representing the axial and hoop strains are characterised firstly by a linear behaviour reflecting an elastic character up to a level of axial compressive load of $30 \mathrm{kN}$ and the linearity limit is established for the three GFRC specimens. Beyond this value of the load, the curves bend by moving away from the linearity reflecting the development of a progressive damage. For reference sample (without fibres) beyond this load level, the crack propagation seems to evolve quickly; it is the typical case of brittle elastic materials. For the other samples, the presence of appropriate amount of fibres delays the sudden damage of materials, but this presence does not provide any ductility at GFRC.

The elasticity modulus E and Poisson's ratio of GFRC cylinders were determined from load-strain curves. The values of elasticity modulus are 21.0, 21.7 and $21.1 \mathrm{GPa}$, whereas the values of Poisson's ratio are: $0.18,0.22$ and 0.24 ; for the samples at 0,1 and $2 \%$ of fibres, respectively. These values are coherent with those found by other authors $(9,29,30)$.

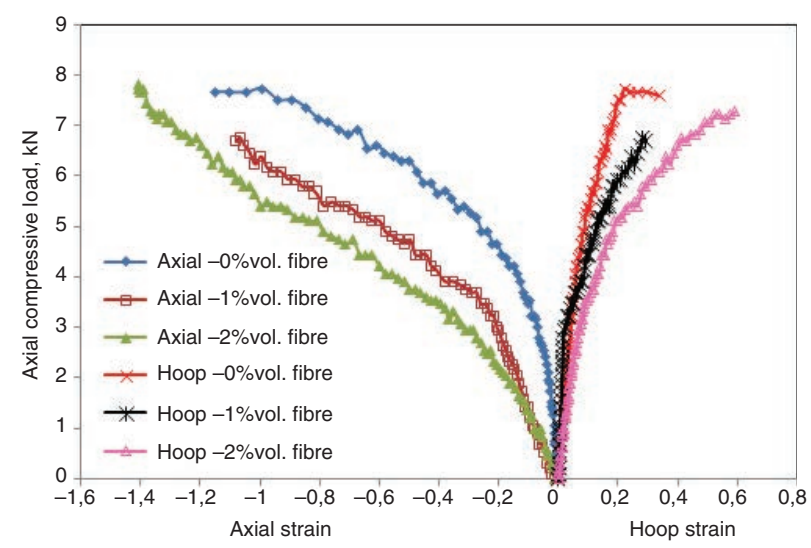

FIGURE 18. Axial compressive load-strain curves of the GFRC. 
The addition of glass-fibres in a cementitious matrix does not provide an improvement in compressive strength as shown in Figure 19. Rather, the rupture stresses of fibrous samples are lower than for the reference sample. Contrary to the flexural tensile strength, the GFRC at long fibres records the sharpest drop of resistance compared to reference sample, because of the concentration of fibre bundles that produce the less compact matrix. This observation is shown by the micrograph displayed in Figure 20, which was observed with a scanning electron microscope (SEM), showing a porous structure. The increase of voids causes a density drop which is growing more with increasing fibres content (Figure 21).

The major advantage of the glass-fibre addition is of obviously the flexural tensile strength gain. This is clearly demonstrated by Figure 22 which shows the evolution of the $R_{f l} / R_{c}$ ratio (flexural tensile strength/compressive strength), the longest fibres are more efficient.

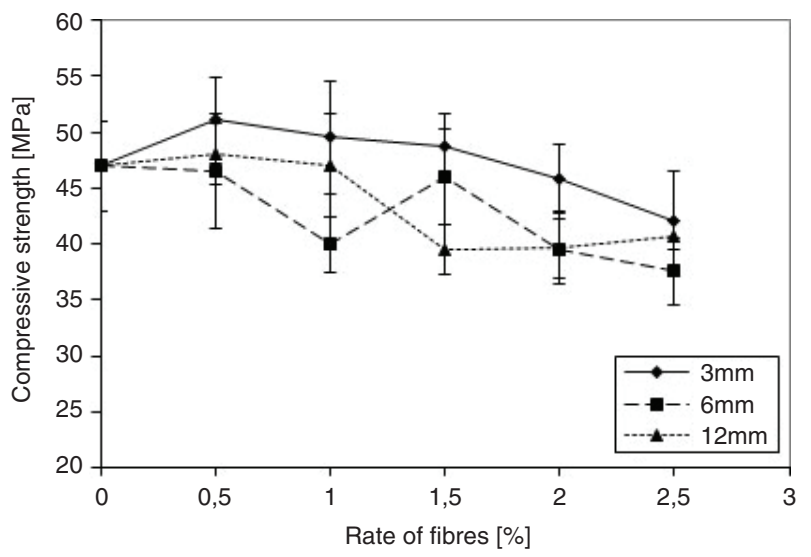

Figure 19. Compressive strength at 28 days of curing.

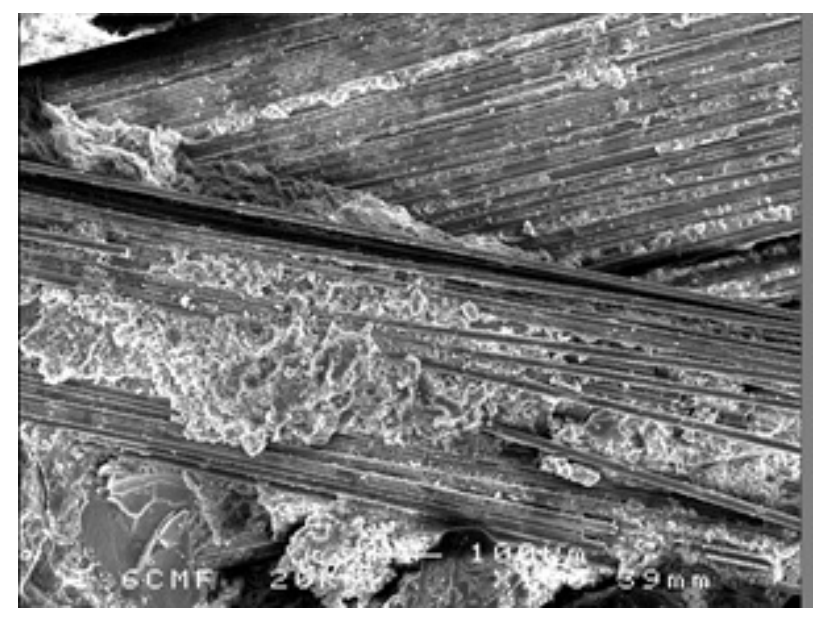

FIGURE 20. SEM image showing a concentration of fibre bundles.

\subsection{Cyclic fatigue testing results}

The results of cyclic fatigue testing are plotted on the $S$ - $N$ diagrams (Wöhler curves) in Figure 23, which indicates the variation of the lifetime of composite expressed in number of cycles in relation to loading level. For fibrous samples, a single fibre length of $12 \mathrm{~mm}$ was tested. In this section, the analysis was restricted to a qualitative description of the results of endurance fatigue testing.

As shown in Figure 23, the lifetime of composites is characterised by a large dispersion, which prevents any forecasting or a fatigue life calculation with a good probability. This dispersion became an admissible fact, as a characteristic of these materials due to their heterogeneous nature $(15,30)$. The local heterogeneousness: composition, grain size, rate, geometry and fibre orientation, distribution of defects, and porosity are practically inescapable.

The specimens tested at $50 \%$ or more of the ultimate stress, are ruptured under a very low number of cycles. It is likely that this load level corresponds to the field of no-linear behaviour of the tested material, i.e., the cracked field. The micro-cracking is not

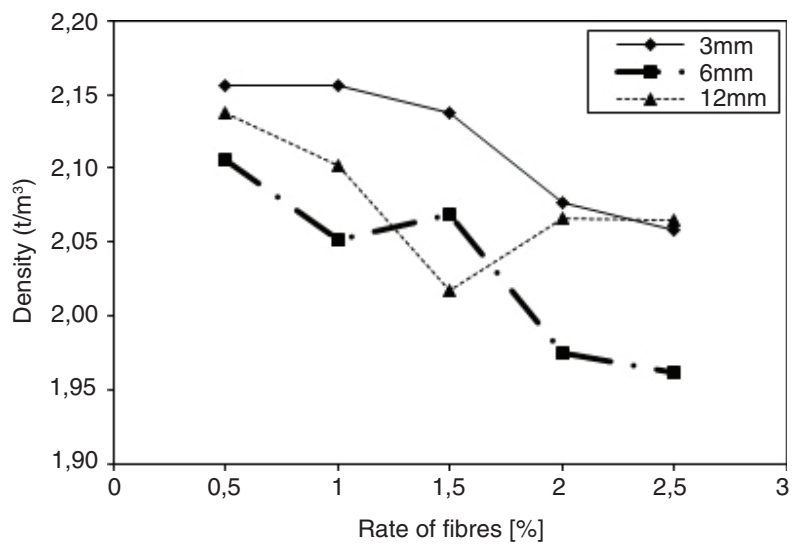

Figure 21. Density evolution measured at 28 days of curing.

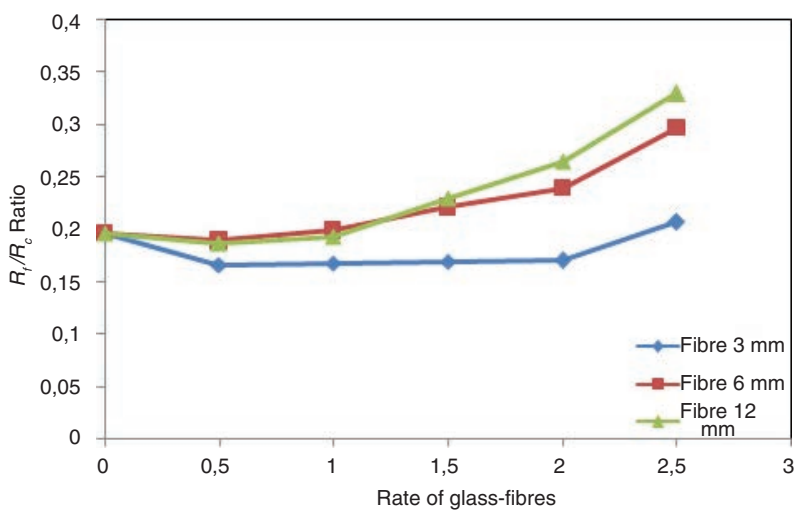

FIGURE 22. Evolution of flexural tensile strength-to-compressive strength ratio. 


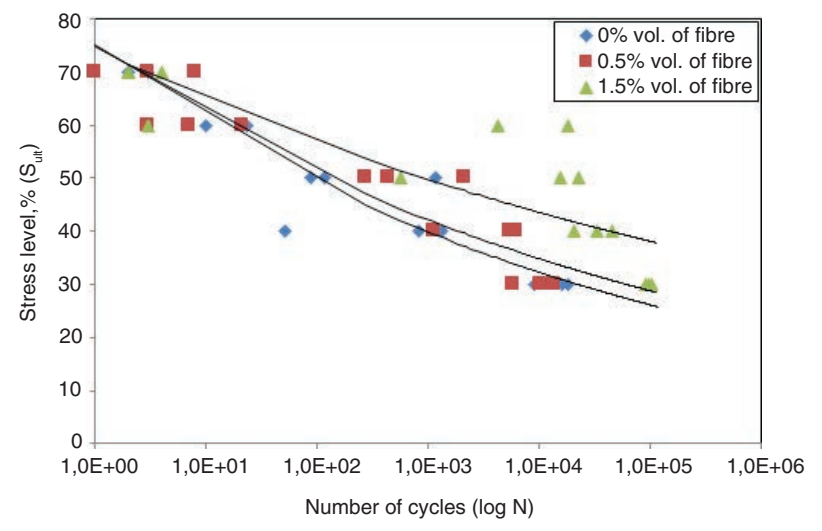

FiguRE 23. $S$ - $N$ diagrams (Wöhler curves).

necessarily visible to the naked eye. The big amplitude of stress will lead to a faster speed of the damage. At this point the fibres do not seem to be involved. What seems likely, after a certain rate of loading, the cyclic stress deteriorates sharply the fibre-matrix interface (31). The major problem of the role of the reinforcements is that, the composites mechanical performances fall when a fraction of reinforcement loses its mechanical effectiveness. Thus, the probability of ruin is much more present when a damage of the fibre-matrix interface is initiated under a cyclic loading. In addition, it should be noted that all events preceding the fatigue rupture depend on a series of random processes whose combining results in significant results dispersion. The presence of different types of damages, developed during a flexural fatigue testing, with parameters difficult to quantify, but which influence the dispersion. On the other hand, the absence of a clear definition of a fatigue rupture criterion remains one of the major sources of the observed dispersions in GFRC lifetime results. The adopted criterion in this study was complete rupture of the specimen. Increasing the fibre content seems to improve the endurance capacity of the material. With low loading rate, the material behaves better at cyclic loads. This confirms some previous studies $(15,29)$, which mention that a low loading ratio is beneficial. However, in the studied range, it does not seem to reveal an endurance limit level.

\section{CONCLUSIONS}

The major conclusions derived from this research study are given below:

- The incorporation of glass-fibres improves the flexural behaviour of GFRC. A synergy (matrix-reinforcement) was observed when the fibre length of $12 \mathrm{~mm}$ and a glass-fibre content of $2 \%$ were applied. Conversely, compressive strength of the GFRC was insensitive to the fibre content.
- The fibre length of $12 \mathrm{~mm}$ does not validate the real behaviour of ductility during flexural loading; the use of glass-fibres longer than $12 \mathrm{~mm}$ could provide answers.

- The glass-fibres in bundles restrict any accurate investigation of glass-cement composites. This disadvantage cannot be solved technically.

- The beneficial effects of glass-fibres make change the rupture character (from brittle rupture to ductile fracture).

- The model of Swamy and Mangat (7) to predict the flexural tensile strength could be a calculation basis for composites of lower fibre content up to $1.5 \%$, but isn't providing a reliable forecasting model. Experimental tests will be the only conclusion basis. The applied model does not take into account the specificity of glass-fibres.

- In cyclic testing, the difficulty to work on a large number of samples prevents to obtain a quantitative analysis to establish a reliable criterion of fatigue rupture. Available results are characterised by their large dispersion, nevertheless release a trend of the material to show a fatigue limit under this load effect. The cyclic tests show the brittle character of GFRC; and even with low-amplitude cycles of loading, no adaptation of this composite can be reported. The number of cycles (approximately 100,000 cycles) obtained for GFRC is too low compared to 2 million cycles obtained from concrete reinforced with metallic fibres.

- The loading rate is not a sufficient parameter to analyse the probability of fatigue rupture of GFRC. At imposed stress will imply significant stress amplitude, which means fast damage speed. This could affect the state of the fibre-matrix interface. This will not necessarily involve a rapid evolution of the deflection which also remains a predominant rupture factor.

\section{ACKNOWLEDGEMENTS}

The author expresses his thanks to Joseph Le Lannic, CMEBA Rennes University, for his assistance with scanning electron microscopy.

\section{REFERENCES}

1. Bentur, A.; Mindess, S. (2007) Fibre reinforced cementitious composites. 2nd edition, Taylor and Francis, London and New York, (2007). ISBN-13: 978-0415250481

2. Banthia, N., Zanotti, C.; Sappakittipakorn, M. (2014) Sustainable fiber reinforced concrete for repair applications. Constr. Build. Mater. 67, 405-412. https://doi. org/10.1016/j.conbuildmat.2013.12.073

3. Zanotti, C.; Banthia, N.; Plizzari, G. (2014) A study of some factors affecting bond in cementitious fiber reinforced repairs. Cem. Concr. Res. 63, 117-126. https://doi. org/10.1016/j.cemconres.2014.05.008 
4. Swamy, R.N. (1975) Fibre reinforcement of cement and concrete. Mater. Struc. 8 [3], 235-254. https://doi.org/10.1007/ BF02475172

5. Mai, Y.W. (1979) Strength and fracture properties of asbestos-cement mortar composites. J. Mater. Sci. 14, 2091-2102. https://doi.org/10.1007/BF00688413

6. Majumdar, AJ; Swamy, R.N.; Bar-Shlomo, S.; Collet, Y. (1977) Fibre concrete materials. Mater. Struc. 10 [56], 103120. https://doi.org/10.1007/BF02474859

7. Swamy, R.N.; Mangat, P.S. (1974) Influence of fiber geometry on the properties of steel fiber reinforced concrete. Cem. Concr. Res. 4, 451-465. https://doi.org/10.1016/ 0008-8846(74)90110-0

8. Rossi, P. (2013) Influence of fibre geometry and matrix maturity on the mechanical performance of ultra highperformance cement-based composites. Cem. Concr. Res. 37, 246-248. https://doi.org/10.1016/j.cemconcomp.2012. 08.005

9. Desai, T.; Shah, R.; Peled, A.; Mobasher, B. (2003) Mechanical Properties of Concrete Reinforced with AR-Glass Fibers. Proc of the 7th international symposium on Brittle Matrix Composites (BMC7) in Warsaw, Poland, 223-232. http://www.academia.edu/2714179/

10. Barhum, R.; Mechtcherine, V. (2013) Influence of short dispersed and short integral glass fibres on the mechanical behaviour of textile-reinforced concrete. Mater. Struc. 46, 557-572. https://doi.org/10.1617/s11527-012-9913-3

11. Bakhshi, M; Barsby, C; Mobasher, B. (2014) Comparative evaluation of early age toughness parameters in fiber reinforced concrete. Mater. Struc. 47, 853-872. https://doi. org/10.1617/s11527-013-0098-1

12. Yap, S.P.; Bu, C.H.; Alengaram, U.J.; Mo, K.H.; Jumaat, M.Z. (2014) Flexural toughness characteristics of steelpolypropylene hybrid fibre-reinforced oil palm shell concrete. Mater. Desig. 57, 652-659. https://doi.org/10.1016/ j.matdes.2014.01.004

13. Goel, S; Singh, S.P. (2014) Fatigue performance of plain and steel fibre reinforced self-compacting concrete using $\mathrm{S}-\mathrm{N}$ relationship. Eng. Struc. 74, 65-73. https://doi.org/ 10.1016/j.engstruct.2014.05.010

14. Sakin, R.; Ay, I.; Yaman, R. (2008) An investigation of bending fatigue behaviour for glass-fibre reinforced polyester composite materials. Mater. Desig. 29, 212-217. https:// doi.org/10.1016/j.matdes.2006.11.006

15. Naaman, A.E.; Hammoud, H. (1998) Fatigue characteristics of high performance fibre-reinforced concrete. Cem. Concr. Comp. 20, 353-363. https://doi.org/10.1016/ S0958-9465(98)00004-3

16. Houari, H; Benkechkache, G; Debicki, G. (2014) Flexural fatigue performance of metal steel fibre reinforced mortar - Influence of fibre aspect ratio and type. Constr. Build. Mater. 58, 166-170. https://doi.org/10.1016/j.conbuildmat. 2014.02.016

17. Savastano Júnior, H.; Santos, S.F.; Radonjic, M.; Soboyejo, W.O. (2009) Fracture and fatigue of natural fibre-reinforced cementitious composites. Cem. Concr.
Comp. 31 [4], 232-243. https://doi.org/10.1016/j.cemconcomp.2009.02.006

18. Schijve, P. (2004) Fatigue of structures and materials. 2nd edition, Klumer Academic Publishers; London, New York and Moscow, (2004). ISBN 978-1-4020-6808-9

19. Lee, M.K.; Barr, B.I.G. (2004) An overview of the fatigue behaviour of plain and fibre reinforced concrete. Cem. Concr. Comp. 4, 299-305. https://doi.org/10.1016/ S0958-9465(02)00139-7

20. EN 197-1. (2011) Composition, specifications and conformity criteria for common cements. Cement - Part 1.

21. ASTM C494-86. (2004) Standard specification for chemical admixtures for concrete. American Society for Testing and Materials, West Conshohocken, USA.

22. Gao, S.L.; Mäde,r E.; Plonka, R. (2004) Coatings for glass fibres in a cementitious matrix. Acta Materialia 52, 4745-4755. https://doi.org/10.1016/j.actamat.2004. 06.028

23. Langlois, V.; Fiorio, B.; Beaucour, A.L.; Cabrillac, R.; Gouvenot, D. (2007) Experimental study of the mechanical behaviour of continuous glass and carbone yarn-reinforced mortars. Constr. Build. Mater. 21, 198-210. https://doi. org/10.1016/j.conbuildmat.2005.06.048

24. ASTM C 1018-92. (1992) Standard test method for flexural toughness and first-crack strength of fibre- reinforced concrete. American Society for Testing and Materials, West Conshohocken, USA, Vol. 04.02, 510-516.

25. JCI Standard SF-4. (1984) Japan Concrete Institute Standards for Test methods of fibre reinforced concrete, Japan, 45-51.

26. Arabi, N. (2011) Influence of curing conditions on durability of alkali-resistant glass fibres in cement matrix. Bull. Mater. Sci. 4, 775-783 https://doi.org/10.1007/ s12034-011-0194-1

27. Girard, F. (2008) Introduction to GFRC (Glass Fiber Reinforced Concrete). The Concrete Countertop Institute. http://www.concretecountertopinstitute.com

28. Rossi, P. (1998) Les bétons de fibres métalliques. Paris: Presses de l'Ecole Nationale des Ponts et Chaussées; Paris (1998). (in French). EAN13 : 9782859782924

29. Barluenga, G; Hernández-Olivares, F. (2007) Cracking control of concretes modified with short AR-glass fibers at early age. Experimental results on standard concrete and SCC. Cem. Concr. Res. 37, 1624-1638. https://doi. org/10.1016/j.cemconres.2007.08.019

30. Tassew, S.T.; Lubell, A.S. (2014) Mechanical properties of glass fiber reinforced ceramic concrete. Constr. Build. Mater. 51, 215-224. https://doi.org/10.1016/ j.conbuildmat.2013.10.046

31. Parant, E.; Rossi, P.; Boulay, C. (2007) Fatigue behavior of a multi-scale cement composite. Cem. Concr. Res. 37, 264-269. https://doi.org/10.1016/j.cemconres.2006.04.006

32. Parant, E. (2003) Mécanismes d'endommagement et comportement mécaniques d'un composite cimentaire, fibre multi-échelle sous sollicitations sévères : fatigue, choc, corrosion. PhD Thesis, ENPC de Paris; (in French). 